\title{
AJKFLUIDS2019-4992
}

\section{HIGH-SPEED FLOW VISUALIZATION OF A CANONICAL AIRBLAST ATOMIZER USING SYNCHROTRON X-RAYS}

\author{
Theodore J. Heindel ${ }^{1}$, Timothy B. Morgan, Thomas J. Burtnett, Julie K. Bothell, and Danyu Li \\ Center for Multiphase Flow Research and Education (CoMFRE) \\ Department of Mechanical Engineering \\ lowa State University \\ Ames, IA 50011-2161 USA
Alberto Aliseda and Nathanael Machicoane
Department of Mechanical Engineering
University of Washington \\ Seattle, WA 98195-2600 USA
}

\begin{abstract}
Liquid sprays play a key role in many engineering processes and the dynamics at the nozzle exit have a significant impact on the downstream spray characteristics. However, visualizing the spray in this region is extremely challenging because, under most operating conditions, the spray is optically dense. High intensity white beam $X$-rays, like those found at the Advanced Photon Source (APS) at Argonne National Laboratory, can be used to produce time-resolved measurements of the liquid-gas structures in the spray near-field region. In this study, high temporal and spatial resolution $X$-ray images were acquired at the 7-BM beamline at APS of an atomization process using a canonical airblast atomizer consisting of coaxial liquid and gas jets. Unique flow structures were observed under various operating conditions, including bag, ligament, wisp, droplet, and air bubble formation, as well as hollowing of the liquid core into a crown at the liquid needle exit. Conditions where these structures exist are presented and their impact on spray formation are discussed.
\end{abstract}

Keywords: High-Speed Imaging, Flow Visualization, Radiography, Synchrotron X-rays, X-ray Imaging.

\section{INTRODUCTION}

Spraying a liquid into a gaseous environment has many practical applications, including food production, coating and painting, additive manufacturing, fire suppression, agricultural applications, pest control, liquid fuel combustion, and cleaning operations. Spray regions are loosely identified as near-field, mid-field, and far-field, and the demarcation between regions is not precise [1]. According to Linne [2], several regions of a spray must be fully visualized and quantified to completely characterize the atomization process. Spray characteristics can easily be visualized and quantified in the mid- and far-field regions using various optical and/or laser diagnostic techniques $[3,4]$. The near-field region has an extremely complex morphology as well as a significant influence on primary atomization. However, near-field measurements are extremely challenging because the spray in this region is typically optically dense, rendering optical and/or laser diagnostics extremely difficult, if not entirely impossible. There are several experimental techniques that can be used to quantify spray characteristics in the near-field region [5]. Several of these techniques utilize X-ray imaging where the minimal refraction of X-rays by phase interfaces allow for high-resolution imaging, even in regions with myriad or complex phase interfaces, and as such are well-suited to study the near field region of sprays. $\mathrm{X}$-ray imaging of sprays has recently been reviewed by Heindel [6] who provides a summary of these techniques.

Synchrotron X-ray imaging uses a high intensity broadband $\mathrm{X}$-ray beam for 2D radiographic imaging with microsecond or sub-microsecond time resolution [7]. It is referred to as white beam radiography because the high intensity beam is composed of a wide range of energies (wavelengths), similar to white light being composed of a range of wavelengths in the visible spectrum. In white beam imaging, the "raw" X-ray beam may pass through filters, typically thin sheets of metal, to remove weakly penetrating (low energy) X-rays. After filtering, the beam passes directly through the object of interest and then onto

\footnotetext{
${ }^{1}$ Corresponding author: theindel@iastate.edu
} 
a detector. One advantage of white beam X-ray imaging in sprays is that structures within a pure liquid core can easily be visualized [8]. Assembling the high-speed white beam radiographs into videos at reduced frame rate can then provide significant insight into the near-field spray dynamics (see, for example, [9, 10]). For example, the white beam imaging capability at the Advanced Photon Source (APS) at Argonne National Laboratory allowed Lin et al. [11] to view the gas-liquid flow dynamics inside a beryllium aerated-liquid injector to characterize the two-phase flow inside the injector as well as estimate the bubble velocity inside the liquid. Halls et al. [7] also used white beam imaging to characterize an impinging jet spray.

In this study, white beam imaging from a synchrotron X-ray source is used to perform high-speed imaging of an airblast atomizer operated over a range of air flow conditions.

\section{EXPERIMENTAL PROCEDURES}

Figure 1a provides a schematic of the airblast nozzle used in this study. The inner aluminum liquid needle has an ID of $\mathrm{d}_{\mathrm{l}}=2.1 \mathrm{~mm}$ and OD of $\mathrm{D}_{\mathrm{l}}=2.7 \mathrm{~mm}$ at the tip, and is coaxial with an outer air chamber $\left(\mathrm{d}_{\mathrm{g}}=10 \mathrm{~mm}\right.$ ID at the tip) fabricated from acetal plastic. Figure $1 \mathrm{~b}$ shows a close-up photograph of the nozzle exit at the conclusion of this study. A precision copper ring was placed around the exit to the air nozzle and was used as an electrical grounding path for a separate study not discussed here. The copper ring prevents imaging into the nozzle region because it is significantly more X-ray attenuating than the fluid inside, limiting the available contrast for imaging. This results in a very dark region where the copper ring is located. Note that a similar airblast nozzle with the same dimensions was used in previous studies, but the outer air chamber was fabricated from aluminum. The aluminum outer nozzle allowed enough X-ray signal through to view the internal flow $[8,10]$. Complete details of the nozzle design can be found elsewhere $[12,13]$ and the open source design ${ }^{2}$ is available.

Figure 2 provides a schematic of the experimental flow loop. An $18.9 \mathrm{~L}$ (5 gal) water tank is filled with distilled water and 5\% by mass of potassium iodide (KI) which is used to increase the X-ray absorption and contrast in the images [6]. The water tank was pressurized with compressed air to provide a constant volumetric flow rate in the inner nozzle. Water exited the tank, passed through a manual ball valve, electronic proportioning (control) valve, and flow meter before entering a plenum on top of the nozzle and then exiting the nozzle via the liquid needle. The flow rate was held constant at $0.099 \mathrm{~L} / \mathrm{min} \pm 5 \%$ using LabView and a simple PID control loop. The water jet exit velocity in this study was $0.48 \mathrm{~m} / \mathrm{s}$, corresponding to a liquid Reynolds number of $\operatorname{Re}_{1}=1,100$ with the water exiting the liquid needle under laminar flow conditions.

\footnotetext{
${ }^{2}$ http://depts.washington.edu/fluidlab/nozzle.shtml
}

(a)

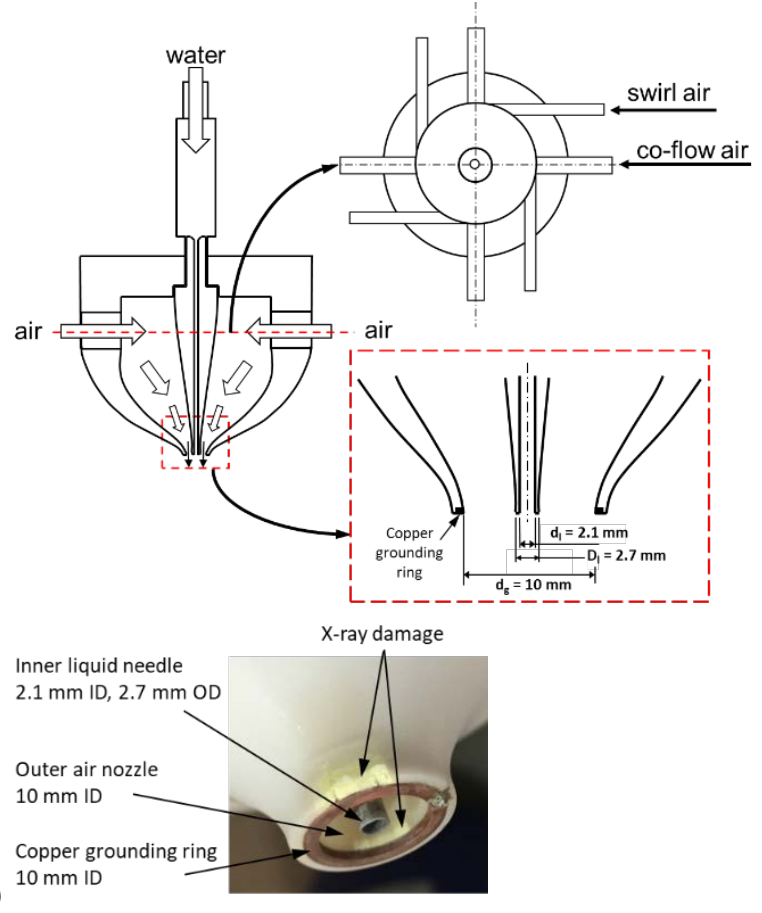

FIGURE 1: (a) SCHEMATIC OF THE AIRBLAST NOZZLE USED IN THIS STUDY AND (b) CLOSE-UP PICTURE OF THE NOZZLE EXIT.

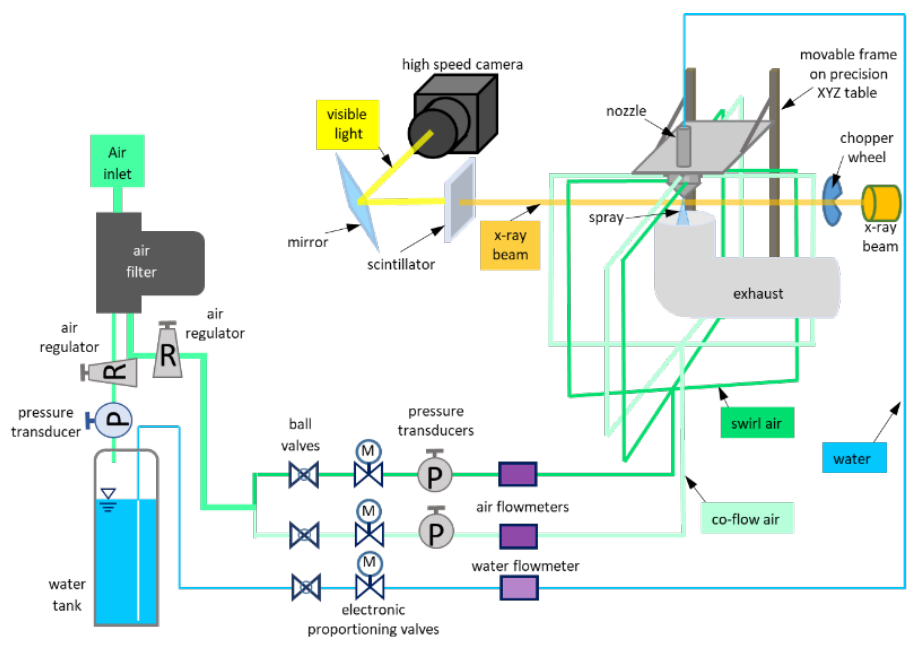

FIGURE 2: WATER AND AIR FLOW LOOP INSTALLED IN THE 7-BM BEAMLINE AT APS.

Compressed air was used as the gas stream in the airblast atomizer. The air was first filtered and then divided into two streams. One stream ("co-flow air" in Figure 1a) passed through a manual ball valve, electronic proportioning valve, and flow meter before being divided into four streams that uniformly entered the converging air nozzle perpendicular to the inner water nozzle. A second stream ("swirl air" in Figure 1a) passed through a separate manual ball valve, electronic proportioning 
valve, and flow meter before being divided into four streams that uniformly entered the converging nozzle tangentially to provide swirl, if desired. The co-flow and swirl air streams were held constant at their desired flow rates $( \pm 5 \%)$ using LabView and a simple PID control loop for each stream.

For the cases in this study, the total gas flow rate ranged 150 to 870 SLPM. For the no-swirl conditions, the swirl air line was closed and all the air entered the nozzle through the co-flow lines, producing a nominal co-flow air exit velocity range of 34 to $200 \mathrm{~m} / \mathrm{s}$; this corresponds to a gas Reynolds number range (based on the gas effective exit diameter of the air stream at the nozzle exit, defined as the diameter of a circle with the same area as the gas exit area) of $\mathrm{Re}_{\mathrm{g}}=21,300$ to 124,000 . In the case of imposed swirl, $50 \%$ of the gas entered through the co-flow line while $50 \%$ entered through the swirl air line, producing a swirl ratio of $\mathrm{SR}=1$.

The atomized water jet was injected into the imaging region before being expelled into an exhaust system. The exhaust system used the building ventilation to pull low-velocity ambient air into the exit stream to prevent recirculation of the atomized spray.

The 7-BM beamline at the APS was used in this study. It was configured similarly to that used by Radke [14] in his white beam studies. Because of the intensity of the white beam $(\sim 0.6$ $\mathrm{W} / \mathrm{mm}^{2}$ ), precautions were taken to limit heating of the experimental equipment. First, the beam is filtered with a 500 $\mu \mathrm{m}$ thick Si filter for the slower frame rate tests, but the filter is removed at the highest frame rate tests to provide more power. Next, the beam passes through a rotating chopper wheel to reduce the time-average power of the beam. The chopper wheel is composed of two $15.2 \mathrm{~cm}$ diameter, $6.35 \mathrm{~mm}$ thick copper discs with two "pie wedge" openings cut into each disc. The discs are arranged such that a common open wedge of about $7.9^{\circ}$ was used. The discs are spun at $0.5 \mathrm{~Hz}$, yielding a burst of X-rays at $1 \mathrm{~Hz}$. Although the chopper wheel is used to limit the average beam intensity, the acetal plastic nozzle still suffered radiation damage at the end of the study, as identified in Figure 1b.

After the chopper wheel, the beam passes through the spray region and then illuminates a $500 \mu \mathrm{m}$ thick YAG:Ce scintillator crystal; limited imaging was also done by replacing this scintillator with a $100 \mu \mathrm{m}$ thick LuAG scintillator crystal. Each scintillator crystal luminesces in the visible spectrum with an intensity proportional to the X-ray intensity. The image on the scintillator is reflected to the high-speed camera via a $45^{\circ}$ mirror.

The high-speed camera was a Photron SA-Z with a speed of 20,000 frames per second (fps) at a full field of view $(1024 \times$ 1024 pixels). Images in this study were acquired at 36,000, 45,000 , and $100,000 \mathrm{fps}$ at reduced field of views. The camera was connected to $180 \mathrm{~mm}$ - $50 \mathrm{~mm}$ macro-coupled lens combination providing an effective magnification of 3.6x. A 1.4x teleconverter was added to this lens combination at the highest frame rates, yielding an effective magnification of 5.04x. Additionally, lead shielding was placed around the imaging equipment to shield it from scattered X-rays. Note that a significant change in this work from previous studies [8, 10, 15, 16 ] is the increased field of view and frame rate provided by the
Photron SA-Z camera and the different magnifications provided by the lens pairings.

Finally, because the white beam is not square (it is wider than it is tall) and the intensity varies from the beam center, flatfield images in which no spray was present were periodically acquired; they were then used to correct for the spatial variation in initial X-ray intensity, which is standard practice in X-ray imaging.

\section{RESULTS}

Figure 3 shows a sequence of four radiographic images taken at 36,000 fps, but only every third frame is shown. All other figures composed of four radiographic images also show every third frame. For the case in Figure 3, $\mathrm{Re}_{\mathrm{l}}=1,100$, $\mathrm{Re}_{\mathrm{g}}=21,300$, and $\mathrm{SR}=0$. Image 1 includes a schematic representation of the liquid needle boundaries, which has $\mathrm{d}_{\mathrm{l}}=2.1$ $\mathrm{mm}$ ID and $\mathrm{D}_{\mathrm{l}}=2.7 \mathrm{~mm}$ OD. In Figure 3 and all subsequent radiographs, the dark streak at the top of each radiograph is the copper grounding ring shown in Figure 1b, and represents the nozzle exit (i.e., all images are of only at the nozzle exit region and encompass the dimensions highlighted in the figure, which is a function of frame size and image magnification). The copper ring appears in all images to be slightly misaligned with the rectangular image. The different heights on the left and right side of the image represent a difference of approximately $100 \mu \mathrm{m}$ in the $5 \mathrm{~mm}$ span. The apparent misalignment could be due to one of three issues (or a combination of all 3): (1) the coper ring was not precisely perpendicular to the rest of the nozzle, (2) the nozzle was not mounted precisely vertical, or (3) the camera was not mounted squarely. It should be noted that care was taken in nozzle assembly and mounting the nozzle and camera, and the $\sim 100 \mu \mathrm{m}$ variation in a $5 \mathrm{~mm}$ span (approximately $1^{\circ}$ ) was deemed acceptable.

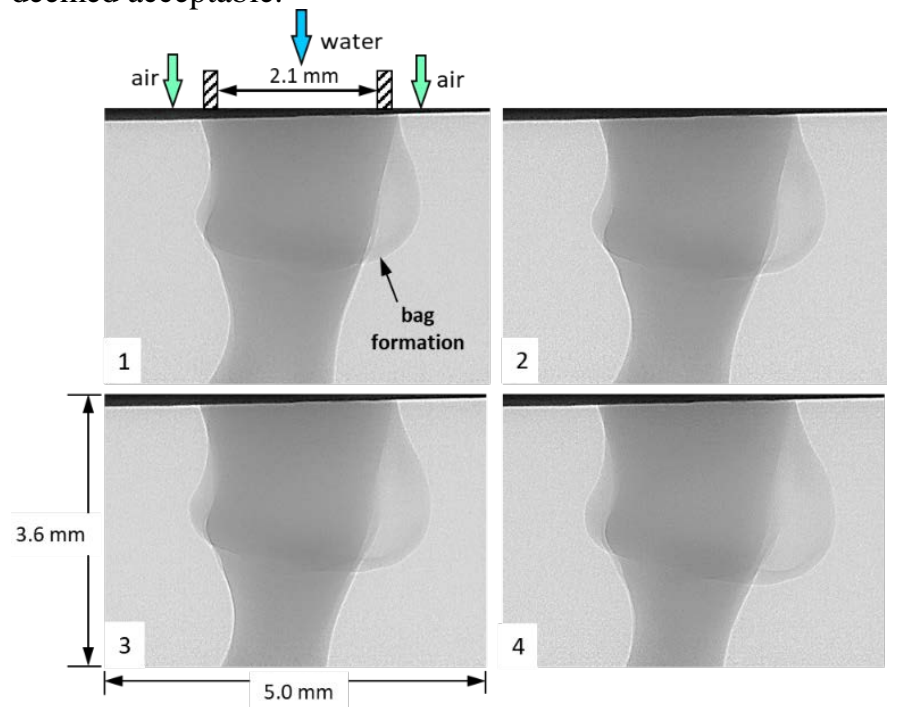

FIGURE 3: IMAGE SEQUENCE RIGHT AT THE NOZZLE EXIT TAKEN AT 36,000 FPS WITH EVERY THIRD FRAME SHOWN

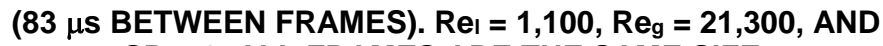
$S R=0$. ALL FRAMES ARE THE SAME SIZE. 
In all images, the liquid corresponds to the darker region. The greyscale level can be correlated to the optical depth of the liquid region, so the darker the region, the more liquid is present between the $\mathrm{X}$-ray source and detector. Instabilities periodically form along the gas-liquid interface in which it appears that the gas tries to penetrate the liquid, forming a bag (identified in image 1). The bag grows and deforms the liquid jet as shown in the image sequence, leading to ligament formation and eventually droplets (which appear much further downstream).

Note that the observations presented here are based on viewing several thousand sequential image frames played back as a video at a much slower playback speed than they were acquired. For example, the acquisition speed used for the conditions in Figure 3 was 36,000 fps, but the typical video playback speed is $30 \mathrm{fps}$, slowing the visualization of the atomization process down by 1200 times.

The character of the spray changes significantly when swirl is imparted to the air stream. Figure 4 shows this result for $\operatorname{Re}_{\mathrm{l}}=1,100, \operatorname{Re}_{\mathrm{g}}=21,300$, and SR $=1$. When swirl is present, bag and ligament formation occur much closer to the nozzle tip and the liquid region substantially deforms. As the gas swirls around the liquid stream, video playback shows the bag breakup occurring in multiple directions, which leads to ligaments being flung out of the liquid core region. For example, Figure 4 shows two distinct ligaments leaving the liquid region on opposite sides.

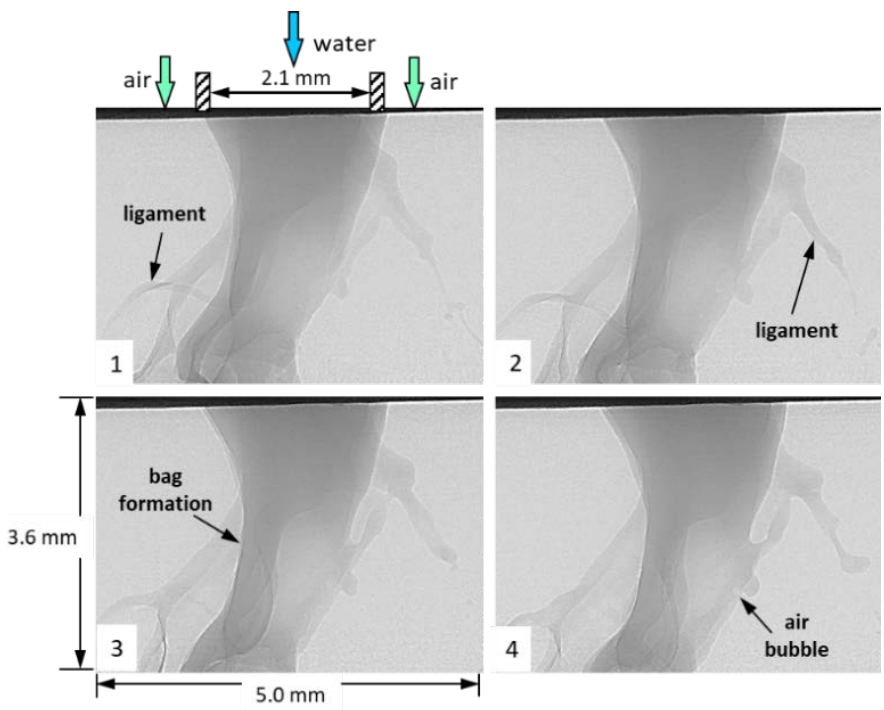

FIGURE 4: IMAGE SEQUENCE RIGHT AT THE NOZZLE EXIT TAKEN AT 36,000 FPS WITH EVERY THIRD FRAME SHOWN (83 $\mu$ S BETWEEN FRAMES). $\operatorname{Re}_{1}=1,100, \operatorname{Re}_{g}=21,300$, AND $S R=1$. ALL FRAMES ARE THE SAME SIZE.

Upon closer inspection of image 4 in Figure 4, a small air bubble is observed that is trapped in the liquid stream. Upon close examination of several X-ray videos, it is hypothesized that the bubbles form during the bag formation process. In some cases, the bags get folded back onto themselves and encloses an air region. Once the outer bag region pinches together, a bubble is formed. Clearly, imaging the dynamics of the bubble formation process is not possible with simple shadowgraphy.

Increasing the gas Reynolds number to $\mathrm{Re}_{\mathrm{g}}=83,800$, while keeping the liquid Reynolds number at $\operatorname{Re}_{\mathrm{l}}=1,100$ drastically alters the liquid structures leaving the nozzle. As shown in Figure 5, with images taken at 45,000 fps, when there is no swirl $(\mathrm{SR}=0)$, it appears that the liquid is pulled or "extruded" from the liquid needle and a wispy crown is formed. The crown forms air bubbles and holes in the liquid region that leads to ligaments and wisp formation approximately one liquid needle diameter downstream.

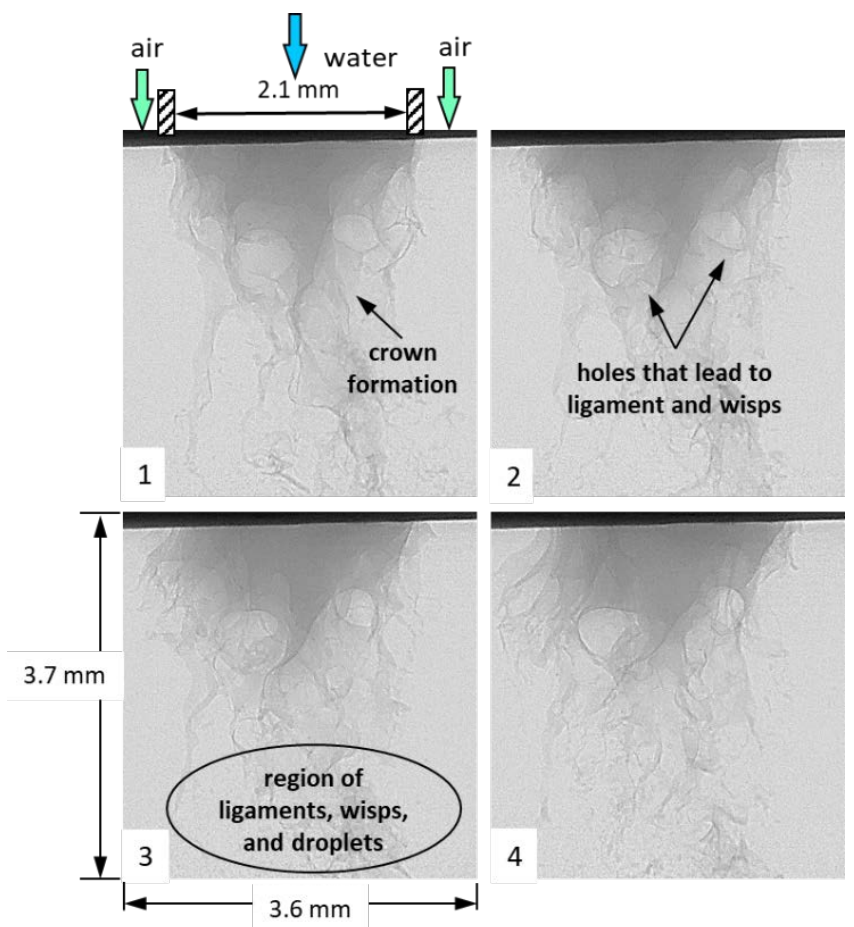

FIGURE 5: IMAGE SEQUENCE RIGHT AT THE NOZZLE EXIT TAKEN AT 45,000 FPS WITH EVERY THIRD FRAME SHOWN (67 $\mu$ s BETWEEN FRAMES). $R_{e}=1,100, R_{g}=83,800$, AND $\mathrm{SR}=0$. ALL FRAMES ARE THE SAME SIZE.

Ligaments are defined as strands of liquid that are primarily one-dimensional and are pulled off the crown or wisp. On the other hand, wisps are thin two-dimensional liquid sheets that are pulled off the liquid crown and may have holes or gaps, but are still connected. Ligaments may form from wisps as the wisp gets stretched and twisted, transitioning into a more one-dimensional structure. In both cases, ligaments and wisps are further pulled apart into micron-sized liquid droplets that are propelled downstream to complete the atomization process.

Adding swirl at this gas Reynolds number (Figure 6) shortens the crown and leads to the formation of ligaments, wisps, and droplets much closer to the nozzle exit. Swirl also promotes an unstable gas core that periodically penetrates the liquid needle and causes sporadic dewetting [16]. Another feature found close to the nozzle are liquid droplets and some of the droplets enclose air bubbles. This is shown in Figure 6 by the 
expanded region. The observed structures are identified as air bubbles and not holes because if they were holes, the liquid droplet would have to be doughnut-shaped, which is unlikely. Also, the air bubbles move with the liquid droplet, and in some cases, more than one air bubble is observed in a liquid droplet. Liquid droplets are also observed farther downstream at lower air flow rates [8], but are not shown here because the focus is right at the nozzle exit.

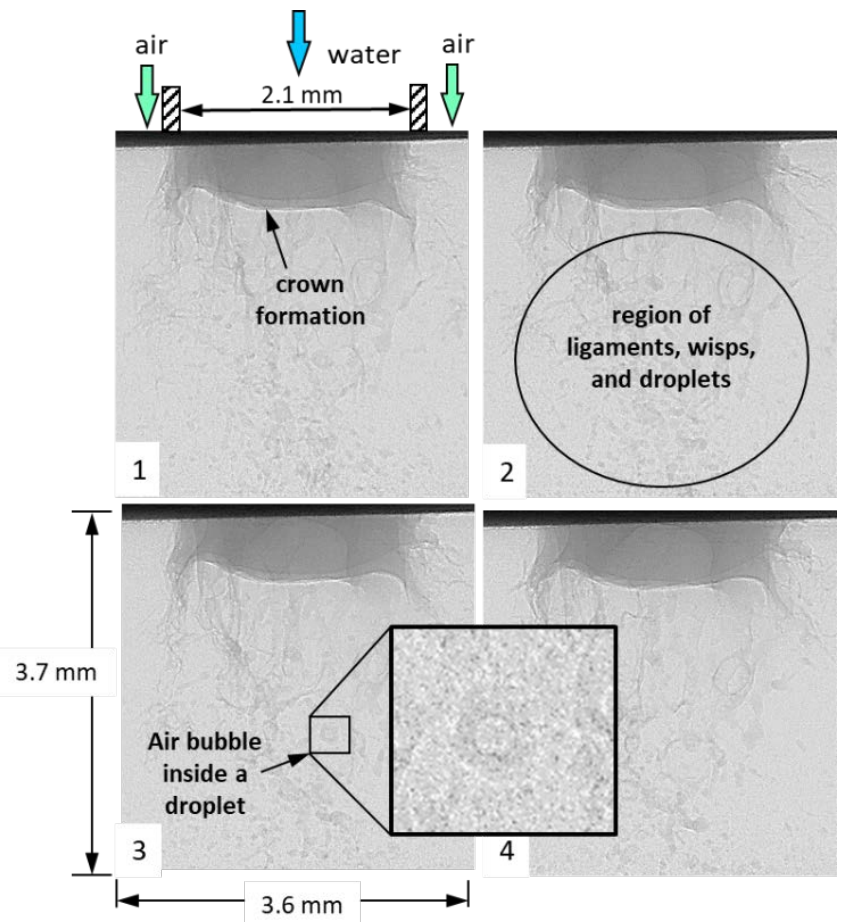

FIGURE 6: IMAGE SEQUENCE RIGHT AT THE NOZZLE EXIT TAKEN AT 45,000 FPS WITH EVERY THIRD FRAME SHOWN (67 $\mu \mathrm{s}$ BETWEEN FRAMES). $\mathrm{Re}_{\mathrm{I}}=1,100, \mathrm{Re}_{\mathrm{g}}=83,800$, AND $S R=1$. ALL FRAMES ARE THE SAME SIZE.

Images were taken at 100,000 fps at the highest air flow rate used in this study $\left(\operatorname{Re}_{\mathrm{g}}=124,000\right)$. In this case, a lens magnification of $5.04 \mathrm{x}$ was used and the imaging region only encompassed $1.62 \times 1.52 \mathrm{~mm}$, which is less than the liquid needle diameter (Figure 7). The high gas flow rate caused the crown to form right at the liquid needle exit and then almost immediately form ligaments and wisps. Hence the crown region is only about 200-500 $\mu \mathrm{m}$ long, and the crown edge is very dynamic. Air bubbles are also clearly observed right at the liquid exit and are caused by recirculation cells forcing air into the liquid needle interior.

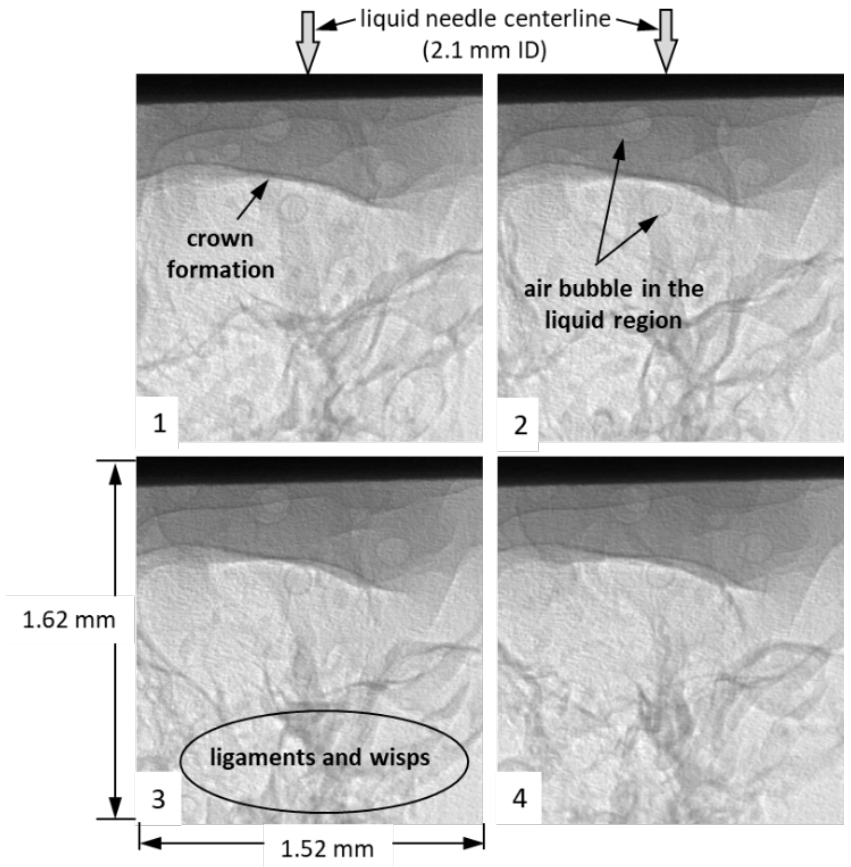

FIGURE 7: IMAGE SEQUENCE RIGHT AT THE NOZZLE EXIT TAKEN AT 100,000 FPS WITH EVERY THIRD FRAME SHOWN (30 $\mu$ S BETWEEN FRAMES). $\operatorname{Re}_{I}=1,100$, $\mathrm{Re}_{\mathrm{g}}=124,000$, AND SR $=0$. ALL FRAMES ARE THE SAME SIZE.

\section{CONCLUSIONS}

High-speed X-ray flow visualization allows unique spray and atomization features to be visualized that are not possible to observe with typical visible light-based visualization techniques. This study used white beam X-ray imaging from the Advanced Photon Source at Argonne National Lab to view the exit region of a canonical airblast atomizer. The formation of bags, ligaments, wisps, droplets, and air bubbles were all observed. Crown formation at higher air flow rates was also captured, showing a very dynamic near-field region.

\section{ACKNOWLEDGEMENTS}

This work was sponsored by the Office of Naval Research (ONR) as part of the Multidisciplinary University Research Initiatives (MURI) Program, under grant number N00014-16-12617. The Photron SA-Z camera was purchased as part of the ONR DURIP program, under grant number N00014-18-1-2380. The views and conclusions contained herein are those of the authors only and should not be interpreted as representing those of ONR, the U.S. Navy, or the U.S. Government.

This work was performed at the 7-BM beamline of the Advanced Photon Source, a U.S. Department of Energy (DOE) Office of Science User Facility operated for the DOE Office of Science by Argonne National Laboratory under Contract No. DE-AC02-06CH11357. The assistance of Dr. Alan Kastengren and Dr. Katie Matusik is greatly appreciated. 


\section{REFERENCES}

[1] Li, D., Morgan, T.B., Pulfer, L.D., and Heindel, T.J., "Measurement of near-field spray characteristics with broadband X-rays," in ASME 2017 FEDSM - Fluids Division Summer Meeting, FEDSM2017-69088. Waikoloa, Hawaii: ASME Press, July 30 - August 3, 2017.

[2] Linne, M., "Analysis of X-ray radiography in atomizing sprays," Experiments in Fluids, Vol. 53 No. 3 (2012): pp. 655-671.

[3] Bachalo, W., "Spray diagnostics for the twenty-first century," Atomization and Sprays, Vol. 10 No. 3-5 (2000): pp. 439-474.

[4] Fansler, T.D. and Parrish, S.E., "Spray measurement technology: A review," Measurement Science and Technology, Vol. 26 No. 1 (2015): pp. 1-34.

[5] Linne, M., "Imaging in the optically dense regions of a spray: A review of developing techniques," Progress in Energy and Combustion Science, Vol. 39 No. 5 (2013): pp. 403-440.

[6] Heindel, T.J., "X-ray imaging techniques to quantify spray characteristics in the near-field," Atomization and Sprays, Vol. 28 No. 11 (2018): pp. 1029-1059.

[7] Halls, B.R., Radke, C.D., Reuter, B.J., Kastengren, A.L., Gord, J.R., and Meyer, T.R., "High-speed, twodimensional synchrotron white-beam X-ray radiography of spray breakup and atomization," Optics Express, Vol. 25 No. 2 (2017): pp. 1605-1617.

[8] Heindel, T.J., Li, D., Morgan, T.B., Bothell, J.K., Aliseda, A., Machicoane, N., and Kastengren, A.L., "X-ray observations in the spray near-field using synchrotron X-rays," in ILASS - Americas 2017: 29th Annual Conference on Liquid Atomization and Spray Systems, Atlanta, GA, May 15-18, 2017.

[9] Heindel, T.J., Bothell, J.K., Li, D., Morgan, T.B., Aliseda, A., Machicoane, N., and Kastengren, A.L., "High-speed X-ray imaging of an airblast atomizer," in 2017 FED Flow Visualization Video Competition, ASME 2017 FEDSM Fluids Division Summer Meeting, Waikoloa, Hawaii: ASME Press, July 30 - August 3, 2017.

[10] Li, D., Bothell, J.K., Morgan, T.B., Heindel, T.J., Aliseda, A., Machicoane, N., and Kastengren, A.L., "High-speed $\mathrm{X}$-ray imaging of an airblast atomizer at the nozzle exit," in 2017 APS-DFD Meeting, pp. 2017 APS-DFD Gallery of Fluid Motion Video Entry \#V0026. Denver, CO, November 19 - 21, 2017, https://doi.org/10.1103/APS. DFD.2017.GFM.V0026.

[11] Lin, K.-C., Kastengren, A.L., and Carter, C., "Exploration of temporal and time-averaged two-phase flow structures using X-ray diagnostics," in ILASS Americas: 29th Annual Conference on Liquid Atomization and Spray Systems, Atlanta, GA, May 15-18, 2017.

[12] Huck, P.D., Machicoane, N., Osuna-Orozcon, R., and Aliseda, A., "Experimental characterization of a canonical two-fluid coaxial atomizer," in ICLASS 2018, 14th Triennial International Conference on Liquid Atomization and Spray Systems, Chicago, IL, July 22-26, 2018.
[13] Machicoane, N. and Aliseda, A., "Experimental characterization of a canonical coaxial gas-liquid atomizer," in ILASS - Americas 2017: 29th Annual Conference on Liquid Atomization and Spray Systems, Atlanta, GA, May 15-18, 2017.

[14] Radke, C.D., An investigation of coaxial rocket injector flows using synchrotron $X$-rays, $\mathrm{PhD}$ Dissertation, Department of Mechanical Engineering, Iowa State University, 2017.

[15] Bothell, J.K., Li, D., Morgan, T.B., Heindel, T.J., Aliseda, A., Machicoane, N., and Kastengren, A., "Characterizing the near-field region of a spray using white beam and focused beam X-ray measurements," in ICLASS 2018, 14th Triennial International Conference on Liquid Atomization and Spray Systems, Chicago, IL, July 22-26, 2018.

[16] Machicoane, N., Bothell, J.K., Li, D., Morgan, T.B., Heindel, T.J., Kastengren, A.L., and Aliseda, A., "Synchrotron radiography characterization of the liquid core dynamics in a canonical two-fluid coaxial atomizer," International Journal of Multiphase Flow, Vol. 115 No. (2019): pp. 1-8. 